\title{
Insights into Desiccation and Self-Healing of Bentonite in Geosynthetic Clay Liners under Thermal Loads
}

\author{
Abbas El-Zein ${ }^{1, *}$, Bowei $\mathrm{Yu}^{1}$, Ali Ghavam-Nasiri ${ }^{1}$ \\ ${ }^{1}$ University of Sydney, School of Civil Engineering, NSW 2006, Australia
}

\begin{abstract}
Geosynthetic Clay Liners (GCLs) are widely used for protecting groundwater from pollution sources at the surface, including applications in which they are subject to significant thermal gradients. Hence, sodium bentonite in the GCL may undergo significant dehydration and cracking, and the GCL might fail as a result. The paper presents outcomes of a set of recent experimental and numerical investigations exploring the propensity of bentonite to desiccate and self-heal, as well as means of mitigating the effect of thermal gradients on the hydraulic conductivity of GCLs. An elasto-plastic thermo-hydro-mechanical model was found to yield reasonable predictions of experimental behaviour, except for the transient phase of preheating hydration. Introducing an airgap between the GCL and the heat source can reduce the extent of desiccation and its effects on hydraulic conductivity. However, the effectiveness of the solution will depend on other factors including subgrade, magnitude of thermal and mechanical loads and type of GCL.
\end{abstract}

\section{Introduction}

Geosynthetic Clay Liners (GCLs) are widely used in barrier systems around the world to protect groundwater from surface pollutants. They are made of a thin layer of sodium bentonite sandwiched between cover and carrier geotextiles and are relatively easy to transport and install. GCLs are typically placed over a layer of natural soil, which provides a crucial source of hydration for the GCL and helps ensure its bentonite maintains low hydraulic conductivity. They are then covered with a high-density polyethylene geomembrane (GMB).

In several engineering applications, GCLs are exposed to significant thermal gradients can cause dehydration and desiccation of the bentonite, with consequent loss of performance [1-10]. These applications include heat-generating organic waste in municipal waste landfills, incineration ash and other industrial waste in hazardous-waste landfills, solar ponds and brine ponds, especially on coal-seam gas extraction sites. Hence, it is important to understand the behaviour of GCLs in such applications in order to ensure adequate protection of underlying aquifers.

Past research on GCLs under thermal loads has led to important insights into their behaviour in single $[1,2]$ and double $[3,4]$ composite liner systems in waste landfills where moderate thermal gradients and high overburden loads $(>200 \mathrm{kPa}$ ) occur. More recently, behaviour under higher thermal gradients and lower loads has been studied numerically [5,6] and experimentally [7-10]. However, significant uncertainties remain about the ability of multi-phase theories of behaviour, including critical-state soil mechanics, to predict bentonite dehydration, desiccation and self-healing under these conditions. In addition, the effectiveness of changes to the design of liner systems, in preventing or mitigating desiccation is of interest and remains an open question.

This paper reports key findings, generated over the last twelve months from a program of research at the University of Sydney. Our focus here is on three research questions. Can thermo-hydro-mechanical models predict experimental observations? Does higher mass per unit area of bentonite reduce desiccation? Does an airgap separating the liner system from the heat source reduce the failure risk? Special attention is paid to bentonite dehydration, desiccation and self-healing.

The paper is structured as follows. First, complexities pertaining to research on GCLs are discussed and placed in the broader context of geotechnical research on bentonite clay. Second, materials and methods are described. Next, key research findings are discussed. Finally, important remaining questions and ongoing investigations are briefly presented.

\section{Complexities of GCL Research}

Five factors add complexity to the study of GCLs. First, GCLs are used under a wide range of environmental and operational conditions and theories describing their behaviour must be able to provide a reasonable coverage of this range. For example, adequate hydration of GCLs by the subsoil, up to gravimetric water contents of $90 \%$ or more, prior to exposure to leachate, is critical. Several factors influence hydration including, amongst others, type and initial water content of underlying soil [e.g., 1112], chemical composition of the leachate and soil water

\footnotetext{
* Corresponding author: abbas.elzein@sydney.edu.au
} 
[e.g., 13-16], temperature [e.g., 17,18], and overburden loads [e.g., 19,20]. These factors vary widely across the different applications in which GCLs are found.

Second, the composite nature of the GCL is such that it is often difficult to infer its behaviour from that of its most important component, namely the thin layer of bentonite. For example, the soil water characteristic curve (SWCC) of the bentonite and that of the geotextiles are very different and, as result, the SWCC of the GCL is usually markedly different to those of their bentonite. Much knowledge has accrued about the behaviour of bentonite over the last few decades, especially as a result of studies focussed on the deep burial of radioactive waste [e.g., 21-23]. However, clay in these repositories is subject to much higher overburden pressures than those typically encountered by a GCL. Hence, while research on bentonite can be useful for understanding GCLs behaviour, a GCL must be considered as a new material with its own properties.

Third, there is significant variability in the bentonite and geotextiles used to manufacture GCLs and empirical observations for one type of GCLs may or may not be relevant to others $[24,25]$. This variability is due to the variety of products on the market and a large and increasing number of manufacturers around the world. The diversity of products and usages is likely to continue, with one market research study estimating 4\% annual growth rate of GCL usage worldwide up to 2022 [26]. For example, either granular or powder bentonite, with different properties, are used in different products and different techniques for holding the components together have been employed (stitch bonding, adhesion, needle-punching). In addition, even for the same product and sometimes within the same roll of GCL, variability of key properties such as mass of bentonite per unit surface area can be high. One important consequence of this variability is that generalising experimental findings must be done with great caution.

Fourth, given the thinness of the bentonite layer typically 7 to $10 \mathrm{~mm}$ - it is difficult to make direct, nondestructive measurements of key mechanical and hydraulic variables in real time. While a GCL can be weighed and its height measured to infer basic volumetric and gravimetric data, it is much more difficult to track changes in real time. As a result, experimental investigations of GCLs typically instrument the subsoil beneath it, or a layer above it, and infer the behaviour of the GCL indirectly.

Finally, key behavioural patterns of GCLs, such as hydration and dehydration, consolidation and thermal loads, occur under conditions of partial, rather than full saturation [27]. Given the fast-evolving state of research in unsaturated soil mechanics, critical theoretical questions remain unanswered, especially in relation to the selection of stress state variables and characterisation and interpretation of soil water characteristic curves. Inevitably, therefore, our understanding of GCLs and our ability to model their behaviour is bound to evolve with the field of partially-saturated soil mechanics.

\section{Materials and Methods}

\subsection{GCLs and Subgrade}

Commercially available GCLs, Elcoseal X-2000 and X3000 (Geofabrics Australia) were used. The needlepunched, thermally-treated GCLs were made of powder Na-bentonite held together by nonwoven polypropylene geotextile covers, with a woven scrim reinforcement added to the carrier side. Key GCLs properties are shown in Table 1. The main difference between the two GCLs is the higher mass per unit area of GCL_B.

Table 1. Basic properties of GCLs

\begin{tabular}{lcc}
\hline Generic name & GCL_A & GCL_B \\
\hline Manufacturers product designation & X2000 & X3000 \\
\hline $\begin{array}{l}\text { Bentonite dry mass/unit area }\left(\mathrm{g} / \mathrm{m}^{2}\right) \\
\text { (measured) }\end{array}$ & 4345 & 4773 \\
$\begin{array}{l}\text { Bentonite dry mass/unit area }\left(\mathrm{g} / \mathrm{m}^{2}\right) \\
\text { (supplier data) }\end{array}$ & 4250 & 4700 \\
$\begin{array}{l}\text { Cover geotextile mass/unit area }\left(\mathrm{g} / \mathrm{m}^{2}\right) \\
\text { Carry geotextile mass/unit area }\left(\mathrm{g} / \mathrm{m}^{2}\right)\end{array}$ & 300 & 330 \\
$\begin{array}{l}\text { Hydrated gravimetric water content } \\
\text { under 20kPa overburden pressure }(\%)\end{array}$ & 183 & 410 \\
\hline
\end{tabular}

The subsoil was a well-graded sand (SW) found in Sydney, Australia (see Table 2). A coarse-grained soil has relatively low water retention, and therefore lower ability to rehydrate the heated GCL, and was hence more likely to approximate a worst-case scenario.

Table 2. Basic properties of subsoil used in this study

\begin{tabular}{ll}
\hline Contents & Values \\
\hline Soil classification & $\mathrm{SW}$ \\
Specific gravity, $G_{\mathrm{s}}(-)$ & 2.65 \\
Saturated hydraulic conductivity, $k_{\mathrm{s}}(\mathrm{m} / \mathrm{s})$ & $3.0 \times 10^{-4}$ \\
Controlled porosity, $n(-)$ & 0.33 \\
Dry density, $\rho_{\mathrm{d}}\left(\mathrm{g} / \mathrm{cm}^{3}\right)$ & 1.78 \\
As placed gravimetric water content, $w(\%)$ & 11 \\
\hline
\end{tabular}

\subsection{Instrumented Laboratory Soil Columns}

The one-dimensional column test apparatus was designed to test composite liner systems under controlled thermal gradients and overburden loads (see Fig. 1). The $600 \mathrm{~mm}$ column was made of polytetrafluoroethylene and held the subsoil and composite liner system, all placed between two temperature control cells. Four TDRs for measuring water content and three temperature sensors were installed along the subsoil depth at $150 \mathrm{~mm}$ intervals. The column was equipped with a loading frame and a LVDT sensor to monitor vertical deformation of the system. For detailed description, readers are referred to $\mathrm{Yu}$ and El-Zein (in press) [28].

All column tests were conducted as follows. First, the GCL specimens with as-received water contents were installed on top of the subsoil, covered by the GMB, then left to hydrate from the subsoil, under isothermal conditions $\left(20 \pm 1^{\circ} \mathrm{C}\right)$ and $20 \mathrm{kPa}$ overburden load. Once bentonite swelling ceased, indicating adequate levels of hydration (44 to 56 days), heating was applied with top and bottom temperatures set at $78 \pm 1^{\circ} \mathrm{C}$ and $20 \pm 1^{\circ} \mathrm{C}$, respectively (average thermal gradient of $96^{\circ} \mathrm{C} / \mathrm{m}$ ). 


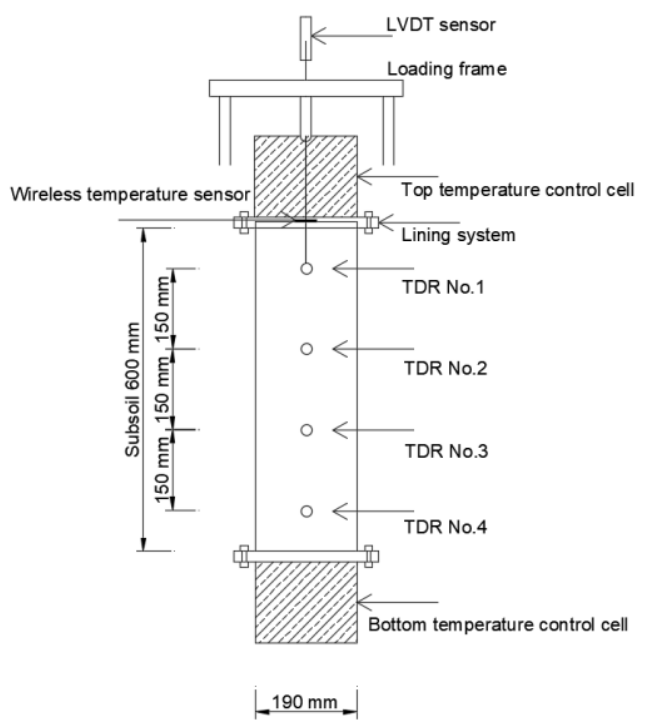

Fig.1. Laboratory column test diagram

Heating continued until no further shrinkage of GCLs was recorded (28 to 39 days). Specimens were then carefully taken out, rehydrated and their permeability to distilled water measured. X-ray images before and after the permeation tests were taken.

This procedure approximated key aspects of site conditions since, in the field, especially under brine ponds, composite liners can be exposed to temperatures up to $80^{\circ} \mathrm{C}$, under a few metres of water as overburden load, and leaks in the GMB may allow brine water to reach and rehydrate the desiccated GCL. Hence, a key measure of performance is the saturated hydraulic conductivity of the rehydrated GCL.

Several aspects of site conditions, however, were not replicated, most importantly the possibility that heating and leakage might occur concurrently rather than successively and that GCLs are permeated with brine rather than distilled water. The implications of these limitations will be discussed later.

Column tests were first conducted for a standard composite liner design (GMB+GCL) using GCL_A (lower mass per unit area of bentonite). Next, two variables were tested for: effects of higher mass per unit area of bentonite (GCL_B) and effects of an air gap between the source of heat and the composite liner, by inserting one or two layers of geo-composites (see Fig. 2). The idea for an air gap was first suggested by Bouazza et al. [7] to reduce thermal load on the GCL, using the low thermal conductivity of air. However, the effectiveness of the solution was not evaluated.

In each test, the following experimental data sets were established in real-time (time series): temperature profile in the subsoil, water content profile in the subsoil, swelling/shrinkage of the bentonite. All column tests were replicated and only minor differences in behaviour were found between original and repeated tests.

\subsection{Numerical Modelling}

The goal of the numerical modelling component of the investigation was to assess whether a multiphase, thermo-hydro-mechanical theory within unsaturated

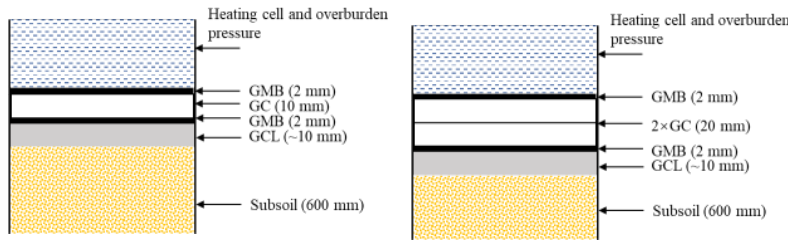

Fig. 2. Design modification of liner (inclusion of air gap)

critical state soil mechanics can reproduce experimental observations. The simulations were conducted with CODE-BRIGHT, in 2D axisymmetric mode, and its associated Barcelona Basic Model (BBM) [29]. Nonlinear elastic and elasto-plastic constitutive equations were used alternately. Solid displacements, liquid and gas pressures, and temperature were adopted as primary state variables. Key model assumptions included small strains and strain rates, pressure- and temperaturedependent constitutive parameters and water retention dependent on void ratio and temperature.

All constitutive parameters of the GCL and the subsoil (water retention curves; thermal and hydraulic conductivities as functions of degrees of saturation or suction; mechanical constitutive parameters etc.) were determined independently of the experimental soil column datasets. To ensure high-quality of experimental validation, and despite the large number of constitutive and boundary-condition parameters in the model, only one parameter (lateral thermal flux) was back fitted to column test experimental results (detailed below).

No-flux boundary conditions for liquid and gas were applied at all boundaries. An overburden load of $20 \mathrm{kPa}$ was specified at the top and no-displacement at all other boundaries. Top and bottom boundary conditions replicated the isothermal hydration stage, followed by the heating stage, as described earlier. Only one boundary-condition parameter used in the model was back-fitted to measured temperatures as follows.

The soil columns were made of low conductivity material and wrapped in insulation foil. However, it was not possible to completely prevent lateral thermal losses. Hence, a constant-flux thermal boundary condition was applied in the simulation at the lateral boundaries and the value of the flux was determined by back-fitting temperature predictions to experimental measurements. The reader is referred to Ghavam-Nasiri, El-Zein, Airey et al. (in press) [30] for more details.

\section{Key Findings}

\subsection{Prediction of temperature, water content, stress and deformation}

Fig. 3 shows predictions of temperature and volumetric water content in the subsoil, and deformation of GCL, compared to experimental results (GCL_A, no air gap). Net stress predictions and x-ray images of dehydrated GCLs are also shown. The stress and deformation graphs show prediction from both non-linear elastic and elastoplastic models. 


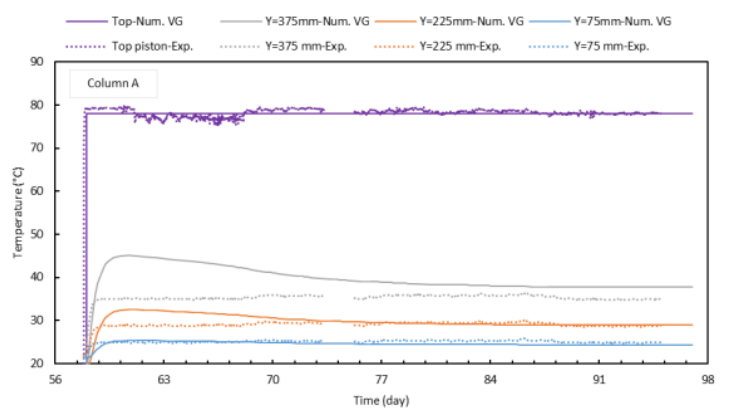

a) Subsoil temperature versus time

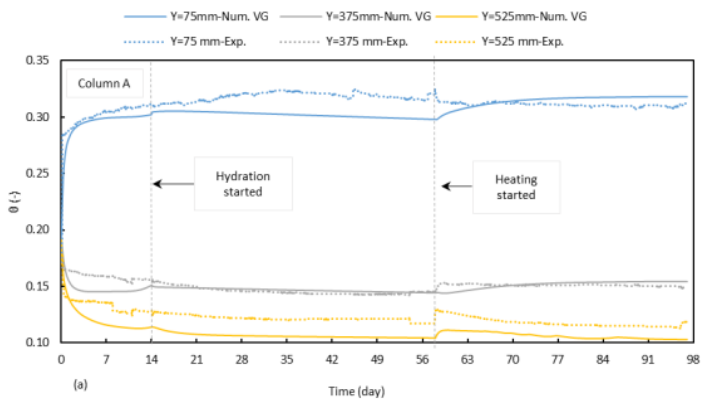

b) Subsoil volumetric water content versus time

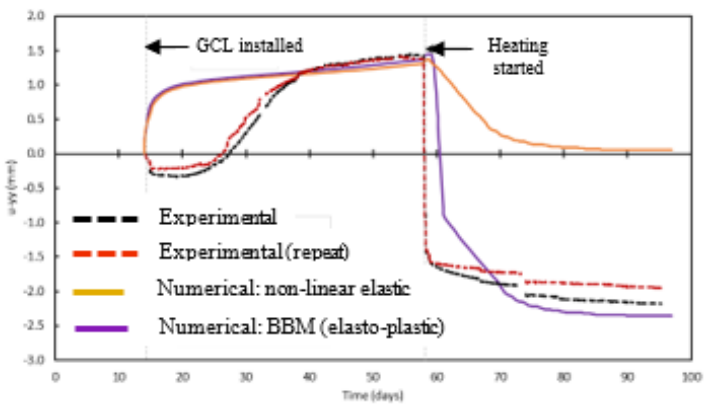

c) GCL deformation

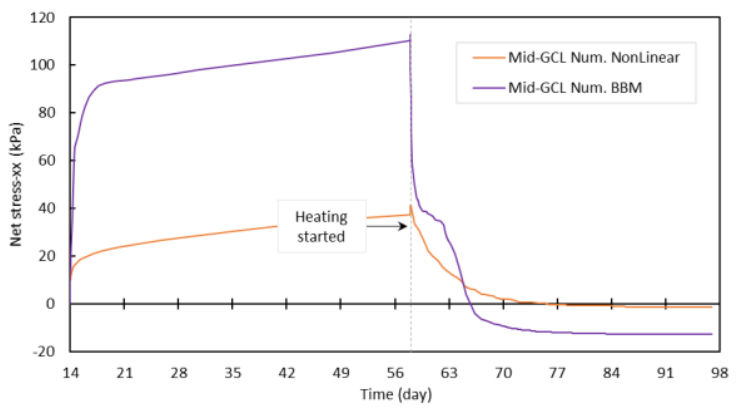

d) predicted net stresses in GCL

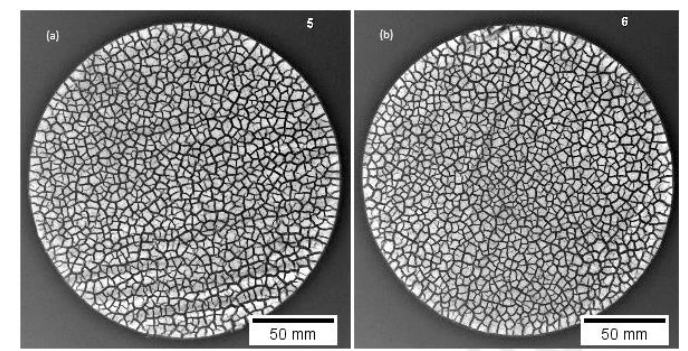

e) X-ray image of desiccated GCLs (with repeat)

Fig. 3. Column tests results for GCL A (solid and dashed lines represent numerical and experimental results, respectively; from Ghavam-Nasiri, El-Zein, Airey et al., in press [30])
The figures show reasonable agreement between experimental and numerical results. The steady-state temperature (Fig. 3a) and water content (Fig. 3b) in the subsoil are well captured but less so the transient responses. Temperature inaccuracy is likely due to the assumption of constant lateral heat flux, when in fact heat flux is likely to be time-dependent. Predictions of shrinkage of bentonite in the GCL were much better when elasto-plastic equations were used (Fig. 3c). However, neither model predicted the slow onset of swelling during the hydration stage. Finally, in the elasto-plastic model, tensile net stresses developed about 10 days after heating started (Fig. 3d), hence qualitatively predicting desiccation revealed by Fig. 3e.

\subsection{Effects of Bentonite Density}

Fig. 4 shows $x$-ray images of desiccated GCL_B specimens after the heating stage. GCL_B has higher mass of bentonite per unit area than GCL A. Both specimens have undergone significant dehydration and desiccation. The residual water contents after heating was slightly higher in GCL_B (8.1 and 9.2\%) compared to GCL_A specimens (7.8 and $8.4 \%$ ).
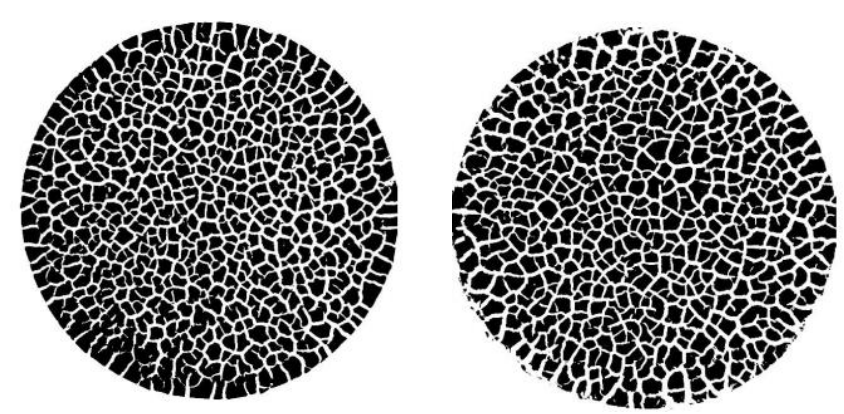

Fig. 4 X-ray image of desiccated GCL_B (with repeat)

Comparing Fig. 3 and Fig. 4, a denser fissuring pattern are seen in GCL_A specimens. This is confirmed by Table 3 which shows results of image analysis software quantifying cracking networks, with a smaller proportion of cracks and larger average crack width in GCL_B specimens. Nevertheless, the results indicate that, under the conditions enacted in the column experiments, higher mass per unit area of bentonite does not appear to reduce desiccation in a significant way.

Table 3. Crack patterns of GCL_A and GCL_B

\begin{tabular}{lll}
\hline & GCL_A & GCL_B \\
\hline Crack area proportion & $33.5 ;$ & $30.4 ;$ \\
$(\%)$ & 37.1 (repeat test) & 31.3 (repeat test) \\
Average crack width & $1.04 ;$ & $1.20 ;$ \\
$(\mathrm{mm})$ & 1.10 (repeat test) & 1.15 (repeat test) \\
\hline
\end{tabular}

\subsection{Effects of Air Gaps}

Case 1 represents the control design with no air gaps. Cases 2 and 3 include one and two 10-mm thick geocomposites, respectively (left and right-hand sides of Fig. 2). The tests were done with GCL_B. 
The presence of airgaps in Case 2 and 3 lowered temperature on top of the GCL specimens from $78 \pm 1^{\circ} \mathrm{C}$ to $51.7^{\circ} \mathrm{C}$ and $43.8^{\circ} \mathrm{C}$ respectively. Correspondingly, the average thermal gradient reduced from $95^{\circ} \mathrm{C} / \mathrm{m}$ for Case 1, to 52 and $39^{\circ} \mathrm{C} / \mathrm{m}$ for Cases 2 and 3 respectively. Fig 5 shows X-ray images before and after rehydration of the specimens. Image analysis did not reveal any significant decrease in crack area proportions $(\sim 30 \%)$. However, the average crack widths of Cases 2 and 3 were 22 28\% smaller than those of Case 1. Examining the postrehydration $\mathrm{x}$-ray images with contrast enhanced, there is evidence of more effective self-healing under lower thermal gradients. This is confirmed by the measurements of hydraulic conductivities for the three Cases shown in Fig 6. The figure shows that the steadystate hydraulic conductivity of the specimen from Case 1 is 2.5 times greater than that of the intact specimen (hydrated, unheated). On the other hand, the hydraulic conductivities of Case 3 and intact specimens are virtually indistinguishable from each other.
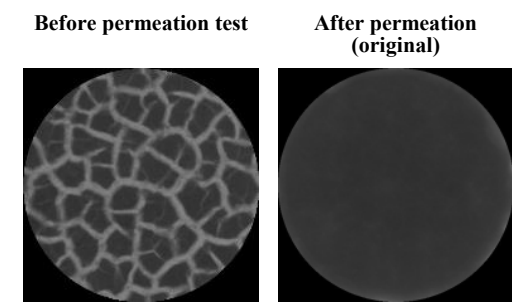

(a) Case 1
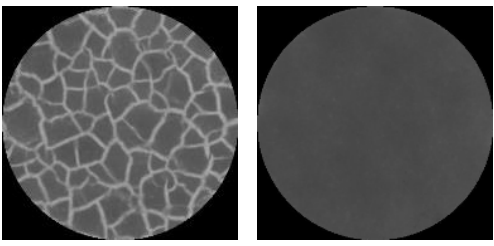

(b) Case 2
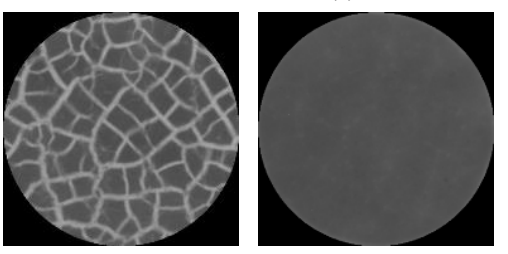

(c) Case 3

Fig. 5 X-ray images of specimens before and after rehydration

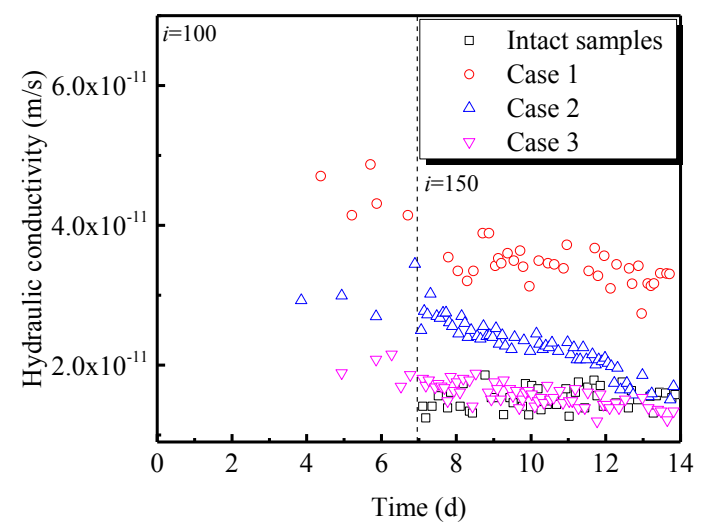

Fig. 6 Hydraulic conductivities of rehydrated GCL specimens

\section{Discussion and Ongoing Research}

The results presented in the previous section show that, using critical state soil mechanics, the thermal, hydraulic and mechanical behaviours of GMB-GCL composite lining systems, when subjected to high thermal gradients and low overburden pressure, can be predicted with reasonable accuracy. Non-linear elasticity predictions of GCL shrinkage upon dehydration were poor but much better results were obtained by an elasto-plastic model.

However, neither framework was able to predict the transient deformation response of the GCL during the hydration phase (prior to heating), namely the delayed swelling of bentonite. There is evidence in the literature that vapour transfer plays an important role in GCL hydration [31], which may explain the lack of swelling in the early stages. Another possible line of enquiry is bentonite's complex porous structure in which water at the early stages of hydration may not have access to the interlayer space of clay particles where significant osmotic swelling takes place. Numerical investigations are currently underway to explore this question.

Two design approaches have been explored (higher mass per unit area of bentonite and air gaps above the liner), neither of which were successful in preventing desiccation under high thermal gradients and low overburden pressure, with a sand as subsoil. However, bentonite in the GCL revealed a remarkable capability for self-healing. When a $20 \mathrm{~mm}$ airgap was introduced, the effect of desiccation on hydraulic conductivity to distilled water practically disappeared upon rehydration. Hence, design features that separate the thermal load from the top of the liner appear promising.

Three other lines of enquiry are possible. First, the composite liner may behave differently depending on the chronological order of desiccation and leakage from the GMB. In this paper, we assumed that thermal dehydration of bentonite occurs before leakage, and rehydration was conducted under isothermal conditions. The response may be different under different scenarios.

Second, rehydration and permeation tests were conducted with distilled water rather than brine or landfill leachate. The well-known chemical reactivity of sodium bentonite, especially its susceptibility to cation exchange, may lead to significant increases in hydraulic conductivity. We are currently measuring the hydraulic conductivities of the specimens with brine as a permeant. In addition, the effect of salt on GCL water retention curves is not well understood and requires further study.

Finally, amending the sandy subsoil to increase its water retention and therefore its ability to rehydrate the GCL may offer the most straightforward solution to the problem and is worth investigating. However, the impact of such modification on the speed and extent of initial hydration of GCL, prior to heat exposure, must be carefully considered before such a solution is adopted.

Research has been partly funded by Australian Research Council Discovery project DP170104192. The authors are grateful to professors R Kerry Rowe, David Airey and Malek Bouazza for their insights and roles in parts of the investigations referred to in this paper. 


\section{References}

1. J.M. Southen, R.K. Rowe. Laboratory investigation of geosynthetic clay liner desiccation in a composite liner subjected to thermal gradients. J Geotech Geoenv Eng 131 (7), 925-935 (2005).

2. J.M. Southen, R.K. Rowe. Modelling of thermally induced desiccation of geosynthetic clay liners. Geotext Geom 23 (5), 425-442 (2005).

3. F.M. Azad, R.K. Rowe, A. El-Zein, D.W. Airey. Laboratory investigation of thermally induced desiccation of GCLs in double composite liner systems. Geotext Geom 29 (6), 534-543 (2011).

4. F.M. Azad, A. El-Zein, R.K. Rowe, D.W. Airey. Modelling of thermally induced desiccation of geosynthetic clay liners in double composite liner systems. Geotext Geom, 34:28-38 (2012).

5. R.K. Rowe, A. Verge A. Prediction of geosynthetic clay liner desiccation in low stress applications. Geosynth Intern 20 (5): 301-315 (2013).

6. J. Ghorbani, A. El-Zein, DW Airey. Thermo-elastoplastic analysis of geosynthetics clay liners under thermal dehydration. Env Geot, in press (2019).

7. A. Bouazza, R.M. Singh, R.K. Rowe, F. Gassner. Heat and moisture migration in a geomembraneGCL composite liner subjected to high temperatures and low vertical stresses. Geotext Geom 42 (5), 555-563 (2014).

8. A. Bouazza, M.A. Ali, W.P. Gates, R.K. Rowe, A. El-Zein. 2017. Heat mitigation in geosynthetics composite liners exposed to elevated temperatures. Geotext Geom, 45 (5):406-417 (2017).

9. A. Ghavam-Nasiri, A. El-Zein, R.K. Rowe, D.W. Airey. 2017. Hydration and desiccation of GCLs in composite lining systems under brine pond conditions: A laboratory investigation. $2^{\text {nd }}$ Int Symp Coupled Phen Env Geot, Leeds, Sep 2017.

10. B. Yu, A. El-Zein, R.K. Rowe. 2018. Effect of bentonite mass per unit area on the desiccation of geosynthetic clay liners under high temperature and low overburden pressure. $11^{\text {th }}$ Intern Conf on Geosynth, Seoul, 16-21 September 2018.

11. B. Chevrier, D. Cazaux, G. Didier, et al. Influence of subgrade, temperature and confining pressure on GCL hydration. Geotext Geomem, 33: 1-6 (2012).

12. G. Siemens, W.A. Take, R.K. Rowe et al. numerical investigation of transient hydration of unsaturated geosynthetic clay liners. Geosynth Intern 19(3), 232-251 (2012).

13. R.J. Petrov, R.K. Rowe, R.M. Quigley. Selected factors influencing GCL hydraulic conductivity. J Geotch Geoenv Eng 123(8):683-695 (1997).

14. D. Guyonnet, E. Gaucher, H. Gaboriau, et al. GCLs interaction with leachate: correlation between permeability, microstructure and surface chemistry. J Geot Geoen Eng 131(6), 740-749 (2005).

15. T. Katsumi, that Are. Fukagawa, R. 2005. Factors affecting the chemical compatibility and the barrier performance of GCLs. In Proc 16th Intern Conf Soil Mech Geotecl Eng (pp. 2285-2288).

16. C. Benson, S. Meer. Relative abundance of monovalent and divalent cations and the impact of desiccation on geosynthetic clay liners. J Geotech Geoenv Eng 135(3):349-358 (2009).

17. R.K. Rowe, M.T. Rayhani, W.A. Take et al. GCL hydration under simulated daily thermal cycles. Geosynth Intern 18(4), 196-205 (2011).

18. A. Barclay, M.T. Rayhani. Effect of temperature on hydration of geosynthetic clay liners in landfills. Waste Manag \& Res, 31(3), 265-272 (2013).

19. M.T. Rayhani, R.K. Rowe, R.W.I. Brachman et al. Factors affecting GCL hydration under isothermal conditions. Geotext Geom, 29(6), 525-533 (2011).

20. G. Siemens, W.A. Take, R.K. Rowe et al. 2013. Effect of confining stress on the transient hydration of unsaturated GCLs. In Proc 18th Int Conf Soil Mech Geotec Eng (pp. 1187-1190).

21. P. Delage, Y.J. Cui, A.M. Tang. Clays in radioactive waste disposal. J Rock Mechanics Geotech Eng, 2(2), 111-123 (2010).

22. A. Zaoui, W. Sekkal. Can clays ensure nuclear waste repositories? Scientific Rep 5, 8815 (2015).

23. C.L. Zhang, N. Conil, G. Armand. Thermal effects on clay rocks for deep disposal of high-level radioactive waste. J Rock Mechanics Geotech Eng 9(3), 463-478 (2017).

24. A. Bouazza. (2002). Geosynthetic Clay Liners (GCLs). In 4th Int Pipel Conf, ASME, A, 211-216.

25. Geosynthetic Research Institute. (2016). Test Methods, Required Properties and Testing Frequencies of GCLs.

26. Grandview Research. 2016. Geosynthetic clay liners market analysis by application. 83 pages.

27. A. Bouazza, J. Zornberg, J.S. McCartney et al. Unsaturated geotechnics applied to geoenvironmental engineering problems involving geosynthetics. Eng Geol, 165, 143-153 (2013).

28. B. Yu, A. El-Zein. Effect of air gaps on dehydration, desiccation and healing of bentonite in geosynthetic clay liners exposed to high temperatures. Geotext Geom (in press).

29. S. Olivella, A. Gens, J. Carrera et al. Numerical formulation for a simulator (CODE_BRIGHT) for coupled analysis of saline media. Eng Comput, 13(7), 87-112 (1996).

30. A. Ghavam-Nasiri, A. El-Zein, R.K. Rowe, D. Airey, M. Bouazza. Thermo-hydro-mechanical simulation of geosynthetics clay liner subject to high temperatures and low overburden pressure. Int $\mathrm{J}$ Geom (in press)

31. A. Bouazza, M.A. Ali, P. Gates, R.K. Rowe. New insight on geosynthetic clay liner hydration: the key role of subsoils mineralogy. Geosynth Intern 24(2), 139-150 (2016). 